\title{
Use of 910 Polyglactin 910 Meshes in Breast Reconstruction
}

\section{Ignacio L Mc Lean*, Julia Barber, Eduardo Beccar Varela, Diana Montoya, Brian Morris, Florencia Costantino, and Constanza Condins Poussif}

Department of Breast Surgery, Breast Center at Hospital Universitario Austral, Pilar, Buenos Aires Province, Argentina

*Corresponding author: Ignacio L Mc Lean, Department of Breast Surgery, Breast Center at Hospital Universitario Austral, Pilar, Buenos Aires Province, Argentina, E-mail: imclean@cas.austral.edu.ar

Received: 22 May, 2020 | Accepted: 15 Jul, 2020 | Published: 22 Jul, 2020

Citation: Mc Lean IL, Barber J, Varela EB, Montoya D, Morris B, et al. (2020) Use of 910 Polyglactin 910 Meshes in Breast Reconstruction. J Surg Open Access 6(5): dx.doi.org/10.16966/2470-0991.223

Copyright: (C) 2020 Mc Lean IL, et al. This is an open-access article distributed under the terms of the Creative Commons Attribution License, which permits unrestricted use, distribution, and reproduction in any medium, provided the original author and source are credited.

\section{Abstract}

Objective: To assess the outcomes in patients undergoing implant-based immediate breast reconstruction assisted with polyglactin 910 mesh.

Materials and Method: Between August 2015 and February 2019, 135 polyglactin meshes (Vicryl and Safir brands) were placed in 100 patients to assist immediate breast reconstruction after mastectomy. Data was collected from clinical records and internal database with patient consent.

Results: There were 32 complications in 25 patients. In 21 cases (84\%) there was some surgical procedure required. There were 7 implants lost (5.2\%), 5 of which belonged to patients that had previous radiotherapy history.

Conclusions: We were able to probe the good adaptation of the polyglactin meshes to the surgical technique, allowing to obtain good results with low complications rate. Patients with radiotherapy are at increased risk of complications and implant losses.

Keywords: Mastectomy; Breast reconstruction; Polyglactin mesh

\section{Introduction}

Over the last decades, due to modern surgical techniques and prosthetic materials refinement, implant based breast reconstruction has shown high improvement in terms of results. Classically, prosthetic implants, either tissue expander or direct to implant, are placed under a muscular pocket made up with the pectoralis major and serratus anterior muscles, which allows a correct coverage but limits the expansion and adequate projection of the new breast. To assist in this implant coverage, different materials have been developed, such as synthetic meshes and biological matrices $[1,2]$. The goal of using these devices is to allow full coverage of the implant without the need to use the serratus anterior muscle, allow a more anatomical reconstruction of the lower pole of the breast, as well as decrease post-operative pain and shorten time to normal life [3].

In recent years, different experiences of prepectoral breast reconstruction [4] assisted by these matrices and meshes have also been published, significantly reducing post-operative pain. Biological membranes, acellular dermal matrices or more complex synthetic meshes have among their disadvantages the high costs, but mainly, at the time of presenting this paper, the lack of availability in our country. However, polyglactin 910 meshes (Vicryl), widely used in different surgical specialties for many years, has proven to be a safe product, with few complications and at much more accessible costs.
Encouraged by earlier reports, in 2015 we began to use polyglactin meshes to assist in prosthetic breast reconstruction.

The aim of our research is to review the outcome of these procedures, focusing on post-operative complications and aesthetic results.

\section{Materials and Method}

Between August 2015 and February 2019, 135 polyglactin meshes (Vicryl and Safir brands) were placed in 100 patients with the aim of assisting immediate breast reconstruction after mastectomy, making these patients our study population.

All patients included in this study were over 21 years old and had an indication for mastectomy, due to a first cancer diagnosis, breast cancer recurrence or risk reduction. Patients in whom meshes were not used, were excluded.

All mastectomies were skin-sparing, with or without preservation of the Nipple-Areola Complex (NAC), with or without axillary procedures when indicated. The implant based reconstruction could be in one or two stages, according to the use of definitive implant or transitory tissue expander. In all cases, aspiration drainage was placed for a time not shorter than 14 days, with antibiotic coverage during that period.

Data was collected from clinical records and internal database with patient consent. 


\section{Results}

Over the analyzed period, 135 meshes were placed in 100 patients. The mean age was 45 years (range 28-70).

In 35 patients, breast reconstruction was bilateral (in 4 of them, mastectomies were performed at two different surgical times) and in 65 cases it was unilateral. The diagnosis is shown in table 1.

No axillary procedure was performed in 61 mastectomies, whereas 59 were associated with axillary sentinel lymph node biopsy, and in 15 cases axillary lymphadenectomy.

Regarding the skin incision of the mastectomy, in 74 cases (55\%) the NAC was preserved; of these 74 cases, 20 mastectomies were due to a cancer diagnosis and did not have relation with a risk reduction procedure. In the remaining 61 mastectomies (45\%), the NAC was resected.

Of the 135 breast reconstructions, in 71 cases (52.5\%) Direct to Implant (DTI) were performed, while in 64 (47.5\%) two-stage Expander-Implant Breast Reconstruction (IBR) were performed.

Regarding the relationship of the cutaneous wound to the mesh: in 87 cases $(64.4 \%)$ the cutaneous wound was not in contact with the mesh, since the muscular plane (pectoralis major) covered that area and the mesh was exclusively at the lower pole of the breast; in 48 cases (35.6\%) the mesh was in contact with the subcutaneous tissue and the surgical wound, either because the muscular plane did not cover this area (39 cases) or because it was a prepectoral breast reconstructions (9 mastectomies).

Patients diagnosed with breast cancer received the following treatments: 31 of them received adjuvant chemotherapy after surgery with the following schemes: 24 received AC followed by Taxanes, 6 cases TC $\times 4$, and in one case, the chemotherapy was neoadjuvant with $\mathrm{AC}$ and Taxanes.

17 patients had a history of radiotherapy prior to surgery, although one of them was bilateral, which means that 18 breast reconstructions were performed on previously irradiated tissues. After surgery, 7 patients underwent radiotherapy of the chest wall. Two other patients were recommended post-mastectomy radiotherapy, but they refused to receive it.

For 92 patients, hospitalization time was one day. Due to inadequate management of post-operative pain, 7 patients spent two days and the remaining patient spent three days at the hospital.

Table 1: Diagnosis in 135 mastectomies.

\begin{tabular}{|l|c|}
\hline \multicolumn{1}{|c|}{ Diagnosis } & Cases \\
\hline Unilateral Mastectomies & 65 \\
\hline$-\quad$ Invasive Carcinoma & 46 \\
\hline$-\quad$ Ductal Carcinoma In Situ & 12 \\
\hline$-\quad$ Contralateral Risk Reduction (CRR) & 7 \\
\hline$-\quad$ Bilateral Mastectomies & 70 \\
\hline$-\quad$ Bilateral Risk Reduction & 32 \\
\hline$-\quad$ Invasive Carcinoma and CRR Mastectomy & 22 \\
\hline$-\quad$ Ductal Carcinoma In Situ and CRR Mastectomy & 14 \\
\hline$-\quad$ Simultaneous Bilateral Invasive Carcinoma & 2 \\
\hline
\end{tabular}

Table 2: Post-operative complications.

\begin{tabular}{|l|c|c|}
\hline Type of Complication & N & $\%$ \\
\hline Wound dehiscence & 14 & 10,4 \\
\hline 3 with implant exposure without loss of it & & \\
\hline Infection & 5 & 3,7 \\
\hline Seroma & 5 & 3,7 \\
\hline 2 with previous radiotherapy and 1 with PMRT & & \\
\hline Hematoma & 3 & 2,2 \\
\hline Capsular contraction & 3 & 2,2 \\
\hline 1 spontaneous & & \\
\hline 2 associated to PMRT & & \\
\hline Flap necrosis & 2 & 1,4 \\
\hline
\end{tabular}

32 post-operative complications were registered immediate to the mastectomy (25 patients) (Table 2).

Of the 25 patients with complications, 21 (84\%) required subsequent surgical intervention (in 7 of them, more than once). However, only 2 cases required re-hospitalization since all interventions were ambulatory.

Of the 64 tissue expanders inserted, at the time of the study the implant replacement was completed in 53 , with placement of definitive implant. In all cases, when performing this second-stage, the total absorption of the previously placed mesh was verified.

After the implant exchange, 4 implant losses were recorded as a consequence of post-operative complications ( 3 of them in previously irradiated breasts, and one in a breast with post-mastectomy radiotherapy -PMRT).

Of the total of 135 breast reconstructions, 7 implants were lost (5.2\%). Of these, 6 cases were mastectomies followed by transitory tissue expander and polyglactin mesh and one case was a mastectomy followed by DTI reconstruction. Of the cases where a tissue expander was placed, one presented mastectomy flap necrosis, requiring removal of the expander and delayed breast reconstruction, and another presented wound dehiscence. The remaining 4 cases of implant loss occurred after replacing the tissue expander with the definitive implant, in 3 due to dehiscence of the wound and exposure of the implant, and in 1 due to infection. It should be noted that these last 4 cases had a previous radiation therapy.

The DTI patient whose implant was lost was due to postoperative infection.

Of the 25 radiotherapy-associated mastectomies (18 before and 7 after mastectomy), 5 cases (20\%) lost the implant due to complications.

Regarding the relationship of the mesh with the cutaneous wound, 5 of the 87 mastectomies (5.7\%) with muscle interposition lost the implant, versus 2 of the 48 mastectomies (4.2\%) where the mesh was in contact with the skin wound.

\section{Discussion}

Since the first publications of acellular matrix or synthetic mesh assisted prosthetic breast reconstruction, the use of these devices has been increasing year after year, allowing the proportion of DTI reconstructions to increase significantly [5]. 
As far as we know, the first publication about the use of polyglactin meshes (Vicryl) in breast surgery was written by Dr. Loustau HD, et al. [2] to assist direct breast reconstruction in a single procedure. Although this type of breast reconstruction is feasible without the help of meshes, its availability is of great help in containing the implant in the muscular pocket and obtaining good aesthetic results [6].

Sometime later, the use of meshes to help breast reconstruction with a tissue expander is described, which facilitates muscle coverage $[7,8]$. We believe that its use in two-stage breast reconstruction is justified, since it allows a greater initial expansion, with a better definition of the lower pole of the breast, better positioning of the inframammary fold, less lateral migration of the implant, less postoperative surgical pain and less time to reach the expected volume [9].

More recently, the use of these devices for prepectoral prosthetic breast reconstruction was described, that is, without detaching of this muscle $[10,11]$. This allows shorter surgical times, avoiding the animated deformity due to contraction of the pectoral muscle, less post-operative pain and faster reintegration into activities of daily living. In this review, we included our first 9 cases with this technique, in which we had no significant complications.

Given that different types of breast reconstruction are included in our study, with a heterogeneous population of patients, it is difficult to draw conclusions regarding the analysis of complications. Of the group of patients with DTI breast reconstruction, only one implant was lost. Nor did we observe a greater number of complications in cases where the polyglactin mesh was in contact with the surgical wound, without a muscle plane interposed at this site. It should be noted that, in the face of suspected complications that put breast reconstruction at risk, active behavior was always chosen, which is reflected in the high percentage $(83.3 \%)$ of patients who underwent a new operation. Other published experiences also show excellent results and low complication rates with polyglactin meshes [12,13].

Among the 7 cases with implant loss and, therefore, loss of breast reconstruction, 4 occurred after the replacement of the tissue expander with the definitive implant and all had a history of radiotherapy before or after mastectomy. This number is below the maximum of $9 \%$ recommended by the guide for oncoplastic breast surgery published in 2012 [14] and the important study by Potter and colleagues [15]. Similar experiences also warn of the increased risk of complications associated with a history of radiation therapy [16-18].

\section{Conclusions}

In conclusion, given that our analysis consists of a retrospective review of case series with a low level of evidence, we consider that it is important to have more follow-up time to evaluate with greater perspective the complications of the use of polyglactin meshes in breast reconstruction. However, in our initial experience, we were able to verify the good adaptation of these meshes to the surgical technique, which allowed us to obtain good initial results with an adequate rate of complications. Likewise, we believe that, in patients irradiated before or after surgery, the probability of complications and eventual loss of the implant is greater, making its complete muscular coverage more recommended.

\section{References}

1. Breuing KH, Warren SM (2005) Immediate bilateral breast reconstruction with implants and inferolateral AlloDerm slings. Ann Plast Surg 55: 232-239.
2. Loustau HD, Mayer HF, Sarrabayrouse M (2007) Immediate prosthetic breast reconstruction: the ensure subpectoral pocket (ESP). J Plast Reconstr Aest Surg 60: 1233-1238.

3. Spear SL, Parikh PM, Reisin E, Menon NG (2008) Acellular DermisAssisted Breast Reconstruction. Aesthetic Plast Surg 32: 418-425.

4. Bernini M, Calabrese C, Cecconi L, Santi C, Gjondedaj U, et al. (2016) Subcutaneous Direct-to-Implant Breast Reconstruction: Surgical, Functional, and Aesthetic Results After Long-Term Follow-Up. Plast Reconstr Surg Glob Open 3: e574.

5. Mennie JC, Mohanna PN, O'Donoghue JM, Rainsbury R, Cromwell DA (2017) National trends in immediate and delayed post-mastectomy reconstruction procedures in England: A seven-year populationbased cohort study. Eur J Surg Oncol 43: 52-61.

6. McLean IL, Montoya D, Beccar Varela E y col. Mastectomia de Reducción de Riesgo. Experiencia del Centro Mamario del Hospital Universitario Austral. Rev Arg Cir (en prensa).

7. Haynes DF, Kreithen JC (2009) Polyglactin mesh in breast reconstruction. Plast Reconstr Surg 124: 62.

8. Moreti E (2015) Uso de expansores tisulares a modo de soporte cutáneo. presentación de un nuevo dispositivo. Cir Plast Iberolatinoam 41: 21-32.

9. Hayes DF, Kreithen JC (2014) Vicryl Mesh in expander/implant Breast Reconstruction: Long-Term Follow-Up in 38 Patients. Plast Reconstr Surg 134: 892-899.

10. Bernini M, Calabrese C, Cecconi L, Santi C, Gjondeda U, et al. (2015) Subcutaneous Direct-to-Implant Breast Reconstruction: Surgical, Functional, and Aesthetic Results after Long-Term Follow-Up. Plast Reconstr Surg Glob Open 3: e574.

11. Nahabedian MY, Glasberg SB, Maxwell GP (2017) Introduction to "Prepectoral Breast Reconstruction". Plast Reconstr Surg 140: 4S-5S.

12. Tessler O, Reish RG, Maman DY, Smith BL, Austen Jr WG (2014) Beyond Biologics: Absorbable Mesh as a Low-Cost, Low-Complication Sling for Implant-Based Breast Reconstruction. Plast Reconstr Surg 133: 90e-99e.

13. Rodríguez-Unda N, Leiva S, Hsu-Tang C, Seal SM, Cooney CM, et al. (2015) Low Incidence of Complications Using Polyglactin 910 (Vicryl) Mesh in Breast Reconstruction: A Systematic Review. J Plast Reconstr Aesthet Surg 68: 1543-1549.

14. Rainsbury D, Willett A (2012) Oncoplastic Breast Reconstruction. Guidelines for Best Practice. BAPRAS.

15. Potter S, Conroy EJ, Cutress RI, Williamson PR, Whisker L, et al. (2019) Short-term safety outcomes of mastectomy and immediate implant-based breast reconstruction with and without mesh (ibra). A multicenter, prospective cohort study. Lancet Oncol 20: 254-266.

16. Evans GR, Schusterman MA, Kroll SS, Miller MJ, Reece GP, et al. (1995) Reconstruction and the Radiated Breast Is there a Role for Implants? Plast Reconstr Surg 96: 1111-1115.

17. Kim T, Cho H (2013) The Suitability of Absorbable Mesh Insertion for Oncoplastic Breast Surgery in Patients with Breast Cancer Scheduled to be Irradiated. J Breast Cancer 16: 84-89.

18. Ganz OM, Tobalem M, Perneger T, Lam T, Modarressi A, et al. (2015) Risk and Benefits of Using and Absorbable Mesh in OneStage Immediate Breast Reconstruction: A Comparative Study. Plast Reconstr Surg 135: 498e-507e. 